\title{
Intracranial Pressure Monitoring in Severe Traumatic Brain Injury - Results of a Canadian Survey
}

\author{
Ramesh Sahjpaul, Murray Girotti
}

\begin{abstract}
Objective: The purpose of this study was to obtain information from Canadian neurosurgeons regarding their opinions on, and utilization of, intracranial pressure (ICP) monitoring for severe traumatic brain injury (TBI). Methods: A brief survey was sent to practicing Canadian neurosurgeons questioning them about their utilization of, and confidence in, intracranial pressure monitoring in the management of patients with severe TBI. Results: One hundred and ninety-six surveys were mailed. There were 103 responses for a response rate of $52.6 \%$. The vast majority of responding neurosurgeons $(98.1 \%)$ utilized ICP monitoring in the management of patients with severe TBI, with most (63.4\%) using it in more than $75 \%$ of their patients, $14.9 \%$ using it in $50-75 \%$ of patients, $14.9 \%$ in $25-50 \%$ of patients, and $6.9 \%$ using it in less than $25 \%$ of patients. The level of confidence that routine monitoring improves outcome from severe TBI ranged from $23.3 \%$ having a low level of confidence, $56.3 \%$ having an intermediate level of confidence, to $20.4 \%$ having a high level of confidence. Most respondents (78.6\%) felt that some form of prospective trial evaluating the role of ICP monitoring in improving outcome from severe TBI was warranted; $17.4 \%$ felt such a trial was not warranted and $3.9 \%$ were uncertain. Conclusions: While ICP monitoring has gained almost universal acceptance among responding Canadian neurosurgeons, their level of confidence that routine monitoring improves outcome from severe TBI was quite variable, with only $20.4 \%$ of respondents having a high level of confidence. Over $75 \%$ of respondents felt that some form of prospective trial evaluating the utility of ICP monitoring is warranted. This information is being used in consideration of a prospective trial addressing this issue.
\end{abstract}

RÉSUMÉ: Surveillance de la pression intracrânienne dans les lésions traumatiques sévères du cerveau - Résultats d'une enquête canadienne. Objectif: Le but de cette étude était d'obtenir de l'information des neurochirurgiens canadiens concernant leur opinion et leur utilisation de la surveillance de la pression intracrânienne (PIC) pour les lésions traumatiques sévères du cerveau (LTC). Méthodes: Un bref questionnaire a été envoyé aux neurochirurgiens canadiens en pratique active concernant leur utilisation et leur confiance dans la surveillance de la pression intracrânienne dans le traitement des patients ayant une LTC sévère. Résultats: Cent quatre-vingt-seize questionnaires ont été postés. Il y a eu 103 réponses, ce qui correspond à un taux de réponse de 52.6\%. La grande majorité des neurochirurgiens qui ont répondu (98.1\%) utilisaient la surveillance de la PIC dans le traitement des patients ayant une LTC, la plupart (63.4\%) l'utilisant chez plus de 75\% de leurs patients, $14.9 \%$ l'utilisant chez 50 à $75 \%$ des patients, $14.9 \%$ chez 25 à $50 \%$ des patients et $6.9 \%$ l'utilisant chez moins de $25 \%$ des patients. Le niveau de confiance que la surveillance de routine améliore l'issue de ces patients était variable, $23.3 \%$ ayant un faible niveau de confiance, $56.3 \%$ ayant un niveau intermédiaire et $20.3 \%$ ayant un niveau de confiance élevé. La plupart des répondants (78.6\%) pensaient qu'il était justifié de faire une étude prospective évaluant le rôle de la surveillance de la PIC dans l'amélioration de l'issue dans les LTC sévères; $17.4 \%$ considéraient qu'une telle étude n'était pas justifiée et 3.9\% étaient incertains. Conclusions: Bien que la surveillance de la PIC soit universellement acceptée chez les neurochirurgiens canadiens ayant répondu à notre questionnaire, leur niveau de confiance que la surveillance de routine améliore l'issue d'une LTC sévère était très variable, seulement $20.4 \%$ des répondants ayant un niveau de confiance élevé. Plus de $75 \%$ des répondants considéraient qu'une étude prospective évaluant l'utilité de la surveillance de la PIC est justifiée. Cette information est prise en considération dans la réflexion sur la pertinence d'une étude prospective sur ce sujet.

Can. J. Neurol. Sci. 2000; 27: 143-147

The role of intracranial pressure (ICP) monitoring and aggressive management of ICP and cerebral perfusion pressure $(\mathrm{CPP})$ in severe traumatic brain injury (TBI) remains controversial. The acceptance and utilization of ICP monitoring in TBI has evolved as evidenced by results from a recent (1997) survey of 1,239 Board Certified neurosurgeons in Canada and the United States conducted as a joint initiative of the American Association of Neurological Surgeons, Joint Section on Neurotrauma and Critical Care, and the Brain Trauma Foundation. ${ }^{1}$ This survey revealed that $83 \%$ felt that most patients with severe TBI should have ICP monitoring; a dramatic increase from a 1991 survey, which revealed that only $28 \%$ of American neurosurgeons routinely used such monitoring. ${ }^{2}$ Reasons for this increase are likely multifactorial and include educational programs and professional development courses

From the Department of Clinical Neurological Sciences, London Health Sciences Center, London, Ontario

RECEIVED NOVEMBER 9, 1999. ACCEPTED IN FINAL FORM FEBRUARY 14, 2000 Reprint requests to: Ramesh L. Sahjpaul, Department of Clinical Neurological Sciences, London Health Sciences Center, University Campus, 339 Windermere Rd, London, Ont N6A 5A5, Canada 
combined with an increased understanding of the pathophysiology of TBI, especially the role of cerebral perfusion pressure (CPP). ${ }^{1}$ Despite the fact that ICP monitoring and aggressive maintenance of CPP have been widely accepted and incorporated into TBI management protocols, there is very little clinical evidence to substantiate their effectiveness; ${ }^{3}$ thus ICP monitoring was designated only a guideline and maintenance of $\mathrm{CPP}>70 \mathrm{~mm} \mathrm{Hg}$ an option in the Guidelines for the Management of Severe Head Injury published in $1996 .{ }^{4}$ It is interesting that despite the almost universal acceptance of ICP monitoring and CPP-based management protocols in the United States and Canada, the situation is very different elsewhere. In the United Kingdom, for example, recent surveys revealed an ICP monitoring rate of approximately 50\% in neurosurgical centers. ${ }^{5,6}$ The purpose of our study was to specifically elicit the opinions of Canadian neurosurgeons regarding ICP monitoring in severe TBI in consideration of a prospective trial to evaluate its utility.

\section{MethodS}

A questionnaire was mailed out to individuals identified from the Canadian Neurosurgical Society Membership list. The majority of individuals included their name in responding. We were able to discount responses from members of the Society practicing outside Canada. When the results of the survey were available, a summary letter was sent to all Canadian neurosurgeons giving them an opportunity to contact us if, for some reason, they had not received the initial questionnaire.

Figure 1: ICP monitoring in severe TBI - results of a Canadian survey (1999)

1. Do you use ICP monitoring in severe TBI?

$$
\text { Yes } \mathrm{n}=101(98.1 \%) \quad \text { No } 2(1.9 \%)
$$

2. If yes, in what percentage of severe TBI cases do you use ICP monitoring? $(n=101)$

Up to $25 \%$ of cases $\quad \mathrm{n}=7 \quad(6.9 \%)$

$25-50 \% \quad 15 \quad(14.9 \%)$

$50-75 \% \quad 15 \quad(14.9 \%)$

$\begin{array}{lll}>75 \% & 64 & (63.4 \%)\end{array}$

3. Please circle how confident you are that routine ICP monitoring improves outcome in severe TBI $(n=103)$.
(n)

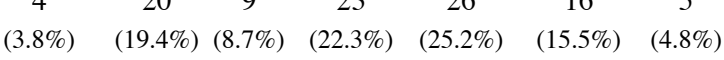
|---------| --------| ---------| ---------| |---------|---------|
1
Not confident
Extremely confident

\begin{abstract}
4. Do you feel a prospective randomized controlled trial assessing whether ICP monitoring improves outcome and quality of life after severe TBI is warranted? $(n=103)$
\end{abstract}

YES $\mathrm{n}=81(78.6 \%) \quad$ NO $18(17.4 \%) \quad$ UNCERTAIN $4(3.8 \%)$

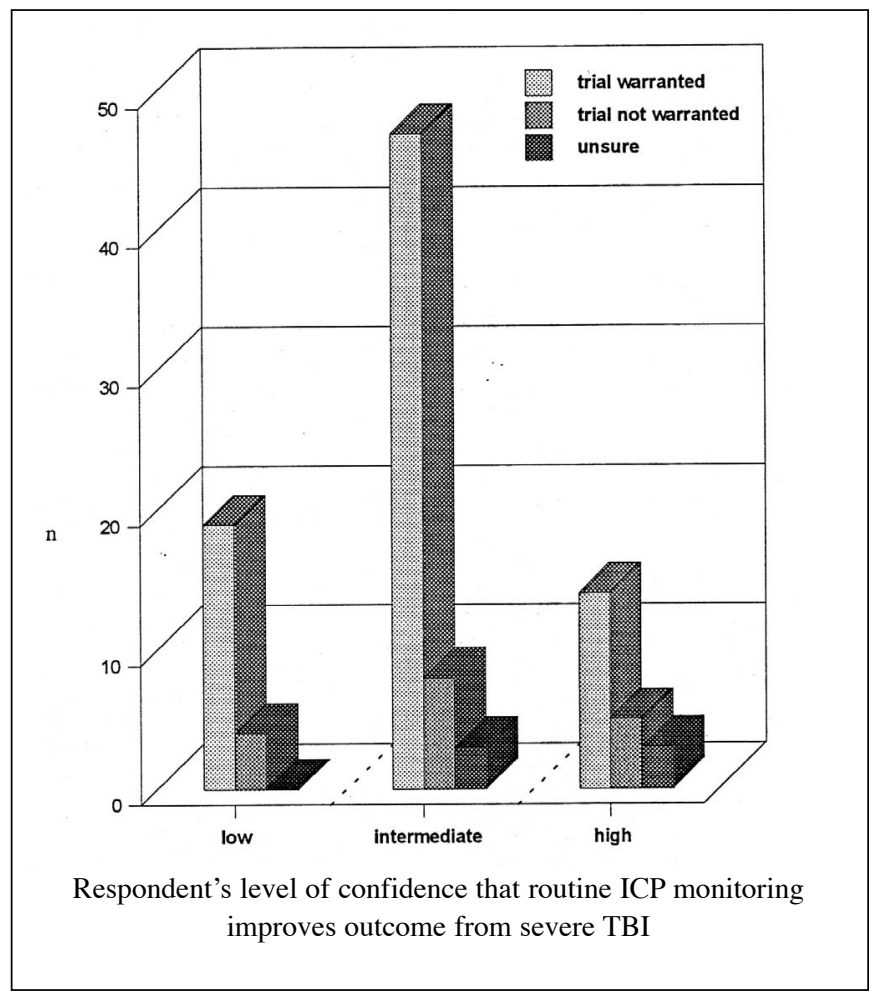

Figure 2: The need for a prospective randomized trial assessing ICP monitoring as a function of respondents' level of confidence that routine monitoring improves outcome from severe TBI $(n=103)$

Question 1 ("Do you use ICP monitoring in severe TBI? Yes/No") and Question 2 ("If yes, in what percentage of severe TBI cases do you use ICP monitoring?") are self-explanatory. Participants were asked to respond to Question 3 ("Please circle how confident you are that routine ICP monitoring improves outcome in severe TBI") on a scale ranging from "not confident" to "extremely confident". Question 4 ("Do you feel a prospective randomized controlled trial assessing whether ICP monitoring improves outcome and quality of life after severe TBI is warranted?") was posed to determine how many neurosurgeons felt that this issue was worthy of rigorous scientific study; in essence, to determine what "should be done" as opposed to what is "being done".

\section{RESULTS}

The survey results are shown in Figure 1. There were a total of 103 responding Canadian neurosurgeons practicing in Canada, for a response rate of 52.6\%. Only two of the 103 respondents (1.9\%) did not use ICP monitoring at all. Of the 101 respondents who used ICP monitoring, most $(63.4 \%)$ used it quite frequently i.e. $>75 \%$ of patients, and only $6(6.95 \%)$ used it infrequently ( $<25 \%$ of patients). Response to Question 3 illustrates that, despite the almost universal use of ICP monitoring, a significant proportion of respondents (23.3\%) had a low level of confidence (Grades 1 and 2 on the response scale) that routine use of ICP monitoring in severe TBI (and the management decisions that result) improves outcome. A similar 
Table: The need for a prospective trial in relation to whether respondents used ICP monitoring $(n=103)$

\begin{tabular}{lcccc}
\hline & Trial warranted & Trial not warranted & Unsure & Total \\
Use ICP monitoring & 79 & 18 & 4 & 101 \\
Do not use ICP monitoring & 2 & 0 & 0 & 2 \\
Total & 81 & 18 & 4 & 103 \\
\hline
\end{tabular}

proportion of respondents $(20.4 \%)$ were quite confident that outcome is improved by ICP monitoring (Grades 6 and 7). The remainder $(56.2 \%)$ had an intermediate level of confidence (Grades 3, 4 and 5). Despite the frequency of use of ICP monitoring, $81(78.6 \%)$ of all respondents felt that a prospective randomized trial assessing the value of routine ICP monitoring in patients with severe TBI was warranted. This sentiment was independent of their level of confidence in the technology (Figure 2) or whether they used ICP monitoring (Table).

\section{DISCUSSION}

\section{Rationale and clinical evidence for monitoring ICP and maximizing CPP in severe TBI}

Historically, the treatment of TBI was based on the pioneering work of Lundberg ${ }^{7}$ and focused on the pivotal role of elevated ICP as a major component in the secondary deterioration in severe TBI. Treatments have therefore attempted to control ICP (barbiturates, hyperventilation, osmotic diuresis, surgical intervention etc.). The Guidelines reviewed the issue of ICP monitoring from an evidence-based perspective and concluded that there is insufficient data to support its use as a Standard. ${ }^{4}$ Despite this, ICP monitoring has become entrenched in clinical practice, certainly in the US and to a large degree in Canada, as evidenced by the results of this survey, with the overwhelming majority of respondents $(98.1 \%)$ using ICP monitoring at least some of the time in the management of severe TBI. The popularity and acceptance of ICP monitoring and aggressive management of ICP was based on clinical studies supporting its use in the 1970s and 1980s. In 1977 Jennett et $\mathrm{al}^{8}$ reported on the outcome from severe TBI in three countries (Scotland, Netherlands and United States). The overall mortality (approximately 50\%) was remarkably similar despite very different management protocols suggesting to some that, with the exception of early evacuation of mass lesions, aggressive neurosurgical intensive care may not improve survival after severe TBI. Unfortunately, the issue of ICP monitoring was not adequately addressed. Soon thereafter, Becker et $\mathrm{al}^{9}$ reported a significantly reduced mortality $(30 \%)$ by use of an intensive management protocol that included ICP monitoring. Subsequently, numerous investigators reported similar improvements in outcome with similar intensive protocols that included ICP monitoring. ${ }^{10-14}$ In 1991 the Traumatic Coma Data Bank (TCDB) reported an overall mortality rate of $36 \%$ from four head injury research centers in the United States (ICP monitoring was central to the management of patients in all four centers). ${ }^{15}$ However, attributing this improved outcome to ICP monitoring is problematic as these studies had significant methodological deficiencies, the most important of which were their use of historical controls and nonrandomized nature. Contradicting this trend of evidence supporting ICP monitoring was a report of $34 \%$ mortality without ICP monitoring ${ }^{16}$ and a prospective randomized study suggesting that patients treated aggressively for elevated ICP did not have a statistically lower mortality than those treated empirically with mannitol regardless of ICP levels. ${ }^{17}$ However, these studies were also methodologically flawed, with the first being non-randomized and subject to selection bias and the second having insufficient sample size.

Justification for ICP monitoring in severe TBI received further support when interest in the role of maintaining adequate CPP mounted. The rationale for optimizing CPP arose from the findings of impaired cerebral blood flow following TBI, both globally and especially in the vicinity of posttraumatic contusions and subdural hematomas and from the frequent histological finding of ischemia in patients who died following TBI. ${ }^{18-26}$ Clinical studies in which CPP was actively maintained above $70 \mathrm{~mm} \mathrm{Hg}$ reported a mean mortality of $21 \%{ }^{27-31}$ in patients with a Glasgow Coma Scale (GCS) score 3-7 substantially lower that the $40 \%$ mortality reported for the TCDB patients within the same GCS range. ${ }^{32}$ However, these studies suffer from the same methodological shortcomings as the ICP studies: they were not randomized studies of CPP management and, in fact, in some of the reports the maintenance of CPP $>70$ $\mathrm{mm} \mathrm{Hg}$ was only a part of routine management, as another treatment was the actual focus of the study. Again, the authors' use of historical controls weakens their conclusions. Indeed, as Chestnut eloquently points out, using historical cohorts in comparing outcomes "... misses a critical confounding side effect of managing patients at elevated cerebral perfusion pressures, which is the pari passu minimization of episodes of hypotension ...," which itself has a very strong association with poor outcome. ${ }^{3}$ To illustrate this point, outcome in a historical cohort of patients who suffered no in-hospital episodes of hypotension was assembled from the TCDB data and compared with outcomes in maximum CPP-based studies; no apparent additional benefit of elevation of CPP over $50 \mathrm{~mm} \mathrm{Hg}$ was demonstrated. ${ }^{3}$

Although ICP measurement and maximum CPP-based algorithms appear to have merit based on physiological principles and our current understanding of the pathophysiology of TBI, it is the lack of irrefutable clinical evidence supporting their effectiveness that has prevented ICP monitoring and the maintenance of CPP $>70 \mathrm{~mm} \mathrm{Hg}$ from being adopted as standards in the Guidelines. ${ }^{4}$ It is also apparent that despite the fact that the 
Guidelines appear to have had a substantial impact on the care of head-injured patients in North America (45\% of respondents stated that the Guidelines had changed their practice $^{1}$ ), neurosurgeons continue to treat patients in ways that they feel are most appropriate. According to the 1997 survey $^{1} 83 \%$ believed most patients should have ICP monitoring and an even greater number $(97 \%)$ believed that CPP should be maintained above 70 $\mathrm{mm} \mathrm{Hg}$, even though the Guidelines had concluded that supportive clinical data for such treatment was clearly lacking. Our survey showed similar ICP monitoring acceptance among Canadian neurosurgeons. Increases in ICP monitoring utilization over the past decade in North America cannot be explained by any changes in the number of practicing neurosurgeons as this has remained relatively constant. In addition, although the higher neurosurgeon to population ratio may explain the greater current utilization of ICP monitoring in the United States compared to the United Kingdom for example, this argument does not explain the almost twofold greater utilization in Canada.

\section{Assessing the value of ICP monitoring: anticipated difficulties with conducting a prospective randomized trial in 1999. Has the time for such a trial passed?}

Despite the time and expense dedicated to TBI research and the plethora of clinical studies addressing ICP and CPP in severe TBI it is certainly sobering that conclusive clinical data are lacking and that a definitive trial has not been performed. There are likely several reasons for this. First, the almost universal acceptance of ICP monitoring in the United States and Canada may pose ethical concerns for such a study, specifically with regards to the treatment of the control (unmonitored) arm (Rosner MJ, Jane J, personal communication). Although there are certainly some neurosurgeons who do not use ICP monitoring and make management decisions based on clinical exam and radiological studies alone, whether there would be a sufficient number who would be willing to randomize their patients to receive no monitoring remains doubtful. Second, ICP monitoring is an integral part of the management of TBI in virtually all head injury research centers and is necessary for assessment of effectiveness of promising new treatments. A case in point is the "Lund protocol" proposed by Dr Eker and colleagues. ${ }^{33}$ In de-emphasizing the effects of secondary cerebral ischemia this protocol contradicts the prevailing view of maximizing CPP and directly challenges conventional treatment. ${ }^{34}$ Using this approach the authors reported a remarkable $8 \%$ overall mortality and $80 \%$ favourable outcome in survivors in a prospective nonrandomized study. Such dramatic improvement compared to conventional treatment outcome will obviously need to be substantiated by a randomized controlled trial comparing their protocol to the "maximum CPP" protocols currently in use, and any such comparison will necessarily require ICP monitoring in both arms. Finally, many clinicians argue that monitoring ICP simply provides additional physiologic data, much the same as monitoring blood pressure with arterial catheters, and should be viewed as such. Of note, a randomized controlled trial to assess the effectiveness of ICP monitoring proposed by the Traumatic Coma Data Bank was not successful in obtaining funding from the National Institute of Health. ${ }^{4}$ It was estimated that to show a $10 \%$ reduction in mortality from $35 \%$ to $25 \%$ (alpha $5 \%$, power $80 \%$ ) the study would require a total sample size of 768 patients, a multi-center design, and approximately 4-5 years to complete at a cost of over $\$ 5$ million US. For the above reasons, while such a trial would be useful from the perspective of pure scientific inquiry, any potential impact on clinical practice, at least in North America, is at best questionable. In addition, a negative result might foster the nihilistic attitudes held by many that aggressive treatment of severe TBI is futile, and possibly hinder attempts to evaluate promising new treatments, such as the "Lund protocol." It is interesting that in our survey over three quarters of respondents (78.6\%) felt a critical appraisal of ICP monitoring in the form of a randomized controlled trial would be useful (a reflection of the fact that, despite almost universal utilization, only one fifth of respondents had a high level of confidence that routine ICP monitoring improves outcome). Selection bias is obviously a concern with a response rate of only $52.6 \%$, but this rate is substantially better than the 39\% response rate in the 1997 survey conducted by the Joint Section on Neurotrauma and Critical Care. ${ }^{1}$ A crucial question that unfortunately was neglected in our survey would have asked respondents if they would randomize their patients if such a study were performed in Canada.

\section{REFERENCES}

1. Marion DW, Firlik K. Management of Severe Traumatic Brain Injury in 1997: The Impact of the Guidelines for the Management of Severe Head Injuries. AANS and CNS Joint Section on Neurotrauma and Critical Care. Summer/Fall 1997, p2-3.

2. Ghajar JB, Hariri R, Narayan RK, et al. Survey of critical care management of comatose head injured patients in the United States. Crit Care Med 1995; 23:560-567.

3. Chestnut R. Implications of the Guidelines for the Management of Severe Head Injury for the practicing neurosurgeon. Surg Neurol 1998;50:187-193.

4. Bullock R, Chestnut R, Clifton G, et al. Guidelines for the management of severe head injury. 1996; New York:Brain Trauma Foundation.

5. Jeevaratnam DR, Menon DK. Survey of intensive care of severely head injured patients in the United Kingdom. BMJ 1996;312(70360):944-947.

6. Matta B, Menon D. Severe head injury in the United Kingdom and Ireland: a survey of practice and implications for management. Crit Care Med 1996;24(10):1743-1748.

7. Lundberg N: Continuous recording and control of ventricular fluid pressure in neurosurgical practice. Acta Psychiatr Neurol Scand Suppl 1960;149:1-193.

8. Jennet B, Teasdale G, Galbraith S, et al. Severe head injury in three countries. J Neurol Neurosurg Psychiatry 1977;40:291-295.

9. Becker DP, Miller JD, Ward JD, et al. The outcome from severe head injury with early diagnosis and intensive management. J Neurosurg 1977;47;491-502.

10. Marshall LF, Smith RW, Shapiro HM. The outcome with aggressive treatment in severe head injuries Mannitol dose requirements in brain injured patients. J Neurosurg 1978;48;169-172.

11. Saul TG, Ducker TB. Effect of intracranial pressure monitoring and aggressive treatment on mortality in severe head injury. J Neurosurg 1982;56:498-503.

12. Eisenberg HM, Gary HE Jr, Aldrich EF, et al. Initial CT findings in 753 patients with severe head injury. A report from the NIH Traumatic Coma Data Bank. J Neurosurg 1990;73:688-698.

13. Colohan AR, Alves WM, Gross CR, et al. Head injury mortality in two centers with different emergency medical services and intensive care. J Neurosurg 1989;71:202-207.

14. Ghajar JB, Hariri RJ, Patterson RH. Improved outcome from traumatic coma using only ventricular CSF drainage for ICP control. Adv Neurosurg 1993;21:173-177. 
15. Marmorou A, Anderson RL, Ward JD, et al. Impact of ICP instability and hypotension on outcome in patients with severe head trauma. J Neurosurg 1991;75:S59-S66.

16. Stuart GG, Merry GS, Smith JA, et al. Severe head injury managed without intracranial pressure monitoring. J Neurosurg 1983;59:601-605.

17. Smith HP, Kelly DL Jr, McWhorter JM, et al. Comparison of mannitol regimens in patients with severe head injury undergoing intracranial monitoring. J Neurosurg 1986;65;820-824.

18. Bouma GJ, Muizelaar JP, Choi SC, et al. Cerebral circulation and metabolism after severe traumatic brain injury: the elusive role of ischemia. J Neurosurg 1991;75:685-693.

19. Bouma GJ, Muizelaar JP, Stringer WA, et al. Ultra early evaluation of regional cerebral blood flow in severely head-injured patients using xenon enhanced computed tomography. J Neurosurg 1992;77:360-368.

20. Jaggi JL, Obrist WD, Gennarelli TA, et al. Relationship of early cerebral blood flow and metabolism to outcome in acute head injury. J Neurosurg 1990;72:176-182.

21. Marion DW, Darby J, Yonal H. Acute regional cerebral blood flow changes caused by severe head injuries. J Neurosurg 1991;74;407-414.

22. Roberton CS, Contant CF Narayan RK, et al. Cerebral blood flow, AVDO2, and neurologic outcome in head-injured patients. J Neurotrauma 1992;9:S349-S358.

23. Salvant JB, Muizelaar JP. Changes in cerebral blood flow and metabolism related to the presence of subdural hematoma. Neurosurgery 1993;33:387-393.

24. Graham DI, Ford I, Adama JH, et al. Ischaemic brain damage is still common in fatal non-missile head injury. J Neurol Neurosurg Psychiatry 1989;52;346-350.
25. Graham DI, Lawrence AE, Adams JH, et al. Brain damage in fatal non-missile head injury without high intracranial pressure. J Clin Pathol 1988;41:34-37.

26. Ross DT, Graham DI, Adams JH, et al. Selective loss of neurons from the thalamic reticular nucleus following severe human head injury. J Neurotrauma 1993;10:151-165.

27. Clifton Gl, Allen S, Barrodale P, et al. A phase II study of moderate hypothermia in severe brain injury. J Neurotrauma 1993;10:263371.

28. Fortune JB, Feustel PJ, Weigle CGM, et al. Continuous measurement of jugular venous oxygen saturation in response to transient elevations of blood pressure in head-injured patients. J Neurosurg 1994;80:461-468.

29. Marion DW, Obrist WD, Carlier PM, et al. The use of moderate therapeutic hypothermia for patients with severe head injuries: a preliminary report. J Neurosurg 1993;79:354-362.

30. Rosner MJ, Daughton S. Cerebral perfusion pressure management in head injury. J Trauma 1990;30;933-941.

31. Yoshida A, Shima T, Okada Y, et al. Outcome of patients with severe head injury-Evaluation by cerebral perfusion pressure, In: Nakamura N, Hashiomoto T, Yasue M, eds.:Hong Kong: Springer-Verlag, 1993;309-312.

32. Marshall LF, Gautille T, Klauber MR, et al. The outcome of severe closed head injury. J Neurosurg 1991;75:S28-S36.

33. Eker C, Asgeirsson B, Per-Olof Grande, et al. Improved outcome after severe head injury with a new therapy based on principles for brain volume regulation and preserved microcirculation. Crit Care Med 1998;26(11):1881-1886.

34. Schneck MJ. Treating elevated intracranial pressure: Do we raise or lower the blood pressure? Crit Care Med 1998;26(11):17871788 . 